\title{
APLICAÇÕES AMBIENTAIS DE MICROALGAS
}

\section{ENVIRONMENTAL APPLICATIONS OF MICROALGAE}

\author{
Roberta Schmitz ${ }^{1}$, Clinei Dal Magro ${ }^{2}$, Luciane Maria Colla ${ }^{3 *}$ \\ ${ }^{1}$ Bióloga. Mestranda do Programa de Pós-Graduação em Engenharia/Faculdade de Engenharia e Arquitetura, Universidade \\ de Passo Fundo. E-mail: roberta.schmitz@bol.com.br \\ ${ }^{2}$ Engenheiro Ambiental. Mestranda do Programa de Pós-Graduação em Engenharia/Faculdade de Engenharia e \\ Arquitetura, Universidade de Passo Fundo. E-mail: clineidalmagro@gmail.com. \\ ${ }^{3}$ Engenheira de Alimentos. Doutora em Engenharia e Ciência de Alimentos, Professora do Programa de Pós-Graduação em \\ Engenharia, Universidade de Passo Fundo. E-mail: 1mcolla@upf.br. \\ *Autor para correspondência: Campus I, Prédio L1, Universidade de Passo Fundo - BR 285, Bairro São José - Passo \\ Fundo/RS, CEP: 99052-900 - Cx. Postal 611 - Fone: (54) 3316-8193
}

\begin{abstract}
RESUMO
As microalgas tem sido foco de muitos estudos nos últimos anos tendo em vista sua grande aplicabilidade na indústria de alimentos e farmacêutica, nas áreas da biomedicina e ambiental. As aplicações ambientais das microalgas incluem a biofixação de $\mathrm{CO}_{2}$, remoção de matéria orgânica e metais tóxicos de efluentes, produção de biocombustíveis como biodiesel e bioetanol e na produção de moléculas de origem lipídica com capacidade surfactante entre outros. Dentre as microalgas estudadas, a Spirulina platensis tem apresentado grande potencial de utilização em todos esses setores com destaque especial na área ambiental. Objetivou-se revisar as principais aplicações ambientais dos cultivos microalgais, com ênfase para a microalga Spirulina platensis.
\end{abstract}

Palavras-chave: microalgas; aplicações ambientais; Spirulina platensis.

\begin{abstract}
Microalgae have been focus of many studies in recent years due to its wide applicability in food and pharmaceutical industries and in biomedical and environmental areas. The environmental applications of microalgae include the biofixation of $\mathrm{CO}_{2}$, in the removal of organic matter and toxic metals from wastewater, in the biofuels production, as biodiesel and bioethanol, and in the production of lipid molecules with surfactant activity, among others. Among the studied microalgae, Spirulina platensis has shown great potential in all these sectors with particular emphasis in the environmental area. The objective was to review the main environmental applications of microalgae cultures, with emphasis on Spirulina platensis.
\end{abstract}

Keywords: microalgae, environmental applications, Spirulina platensis.

\section{INTRODUÇÃO}

A preocupação com as questões ambientais tem se tornado cada vez mais evidentes em função da demasiada utilização de recursos naturais em processos produtivos, acarretando assim, um elevado potencial de poluição desses recursos pelas indústrias (BARCELLOS et al., 2009).

A crescente demanda por produtos e serviços tem elevado drasticamente a atividade industrial, gerando cada vez mais resíduos e elevando a utilização dos recursos naturais, os quais estão tornandose escassos e muitas vezes encontram-se poluídos e degradados (DAL MAGRO et al., 2011). Diante desse cenário, busca-se aliar desenvolvimento econômico com proteção ambiental, desenvolvendo-se novos produtos, novas alternativas de processos e técnicas eficientes no combate e remediação da poluição, tornando assim, a atividade industrial menos impactante ao meio ambiente. 
Os processos biológicos tornaram-se uma alternativa interessante no combate a poluição e na geração de novos produtos, uma vez que esses processos utilizam-se do metabolismo microbiano para degradar e remover poluentes (GADD, 2008), bem como para transformar matérias primas gerando produtos menos nocivos ao meio ambiente. Nesses processos, existe uma gama de micro-organismos atuantes, como bactérias (CHEN et al., 2009), fungos (AKAR e TUNALI, 2006) algas e microalgas (SARAVANAN et al., 2009). Neste cenário, destaque tem sido dado às microalgas de diversas espécies, as quais tem sido utilizadas em estudos de tratamento de efluentes e biossorção de metais tóxicos (MEZZOMO et al., 2010; DAL MAGRO et al., 2012), biofixação de $\mathrm{CO}_{2}$ (MORAIS e COSTA, 2007) e produção de biocombustíveis (XU e MI, 2011). Objetivou-se realizar uma revisão de literatura acerca das principais aplicações ambientais de microalgas, com ênfase para a microalga Spirulina platensis.

\section{MICROALGAS}

As microalgas fazem parte de grupo muito heterogêneo de organismos. São predominantemente aquáticos e geralmente microscópicos unicelulares, podendo formar colônias, e apresentar pouca ou nenhuma diferenciação celular. Sua coloração variada é característica oportunizada pela presença de pigmentos e mecanismo fotoautotrófico. Filogeneticamente, as microalgas são compostas de espécies procarióticas ou eucarióticas, antigas ou mais recentes, conforme o período em que surgiram no planeta (RAVEN et al., 2005). O termo "microalgas" não tem valor taxonômico, uma vez que engloba micro-organismos algais com clorofila e outros pigmentos fotossintéticos capazes de realizar a fotossíntese oxigênica (PÉREZ, 2007).

Andrade et al. (2008) e Chisti (2007) caracterizam as microalgas como micro-organismos fotossintéticos, que combinam água e dióxido de carbono atmosférico com luz solar para produzirem várias formas de energia para produzirem biomassa (polissacarídeos, proteínas, lipídios e hidrocarbonetos), que pode ser utilizada na produção de biocombustíveis e suplementos alimentares, e também podem ser empregados na captura de dióxido de carbono da atmosfera. As microalgas produzem mais oxigênio de que todas as plantas juntas existentes no mundo, sendo responsáveis por pelo menos $60 \%$ da produção primária da Terra (CHISTI, 2004).

A biomassa microalgal apresenta cerca de $50 \%$ de carbono na sua composição, assim o fornecimento deste nutriente aos cultivos representa um importante componente dos custos de produção, seja gasoso na forma de dióxido de carbono, ou sólido, principalmente na forma de bicarbonato (VONSAHK, 1997).

Segundo Possatto (2009) para que espécies de microalgas possam produzir satisfatoriamente várias formas de energia, é indispensável cuidados no processo e sistemas de cultivo dos microorganismos, considerando as peculiaridades de cada espécie, adaptação ao ambiente, bem como a disponibilidade de nutrientes associados à viabilidade econômica.

O número exato de espécies de microalgas ainda não é conhecido, mas muitas espécies já podem crescer em sistemas de cultivo. A tarefa mais difícil, no entanto está em cultivar espécies específicas para a produção de óleo (PÉREZ, 2007).

As microalgas existem em um variado número de classes e são distinguidas, principalmente, pela sua pigmentação, ciclo de vida e estrutura celular. As principais linhagens de microalgas em termos de abundância são descritas por RAVEN et al. (2005): a) Diatomáceas (Bacillariophyta), da qual existem aproximadamente 100.000 espécies, sendo considerada a espécie que domina o fitoplâncton dos oceanos, podendo ser encontrada em ambientes de água doce. Apresenta sílica como constituinte da parede celular e a reserva de carboidratos se dá mediante óleo ou polímeros de carboidrato, conhecido como crisolaminarina; b) Algas Verdes (Chlorophyceae, ) representadas por cerca de 17.000 espécies, são encontradas em sua grande maioria, em meio marinho ou em água doce. Sua produção energética de dá principalmente, em forma de amido; c) Algas azuis (Cyanophyta), 
conhecidas por desempenharem papel importante na atmosfera: a fixação de oxigênio. Compreende cerca de 2.000 espécies, podendo ser encontrados em diversos ambientes; d) Algas Douradas (Chrysophyceae) que possuem cerca de 1.000 espécies, com habitat predominantemente doce, são semelhantes às diatomáceas).

\subsection{Spirulina platensis}

O gênero Spirulina compreende cianobactérias filamentosas com elevado teor de proteínas (MONTEIRO et al., 2010). Sua principal característica morfológica é a disposição dos tricomas multicelulares cilíndricos em uma hélice esquerda aberta ao longo de todo o comprimento (TOMASELLI, 1997). Compreendem micro-organismos planctônicos que habitam em corpos de água tropical e subtropical caracterizados por elevados níveis de carbonato e bicarbonato e pH elevado (até 11). Elas tem sido encontradas nos mais diferentes ambientes como águas salobras, mar, piscinas de maré, lagoas salinas, também têm sido encontrada em águas sub-árticas, lagoas tropicais, e fontes de águas termais. Assim, estes organismos parecem ser capazes de adaptação a condições ambientais extremas (CIFERRI e TIBONI, 1985).

Todos os membros do gênero Spirulina são fotoautotróficos, e realizam fotossíntese aeróbica (CIFERRI e TIBONI, 1985), não são capazes de fixar o nitrogênio atmosférico, exceto $S$. labyrinthyformis, uma espécie termofílica isolada de fontes de água quente, sobre a qual foi relatado ser capaz de realizar fotossíntese anoxigênica à custa de sulfuretos (CIFERRI E TIBONI, 1985). São microrganismos fotossintéticos com requerimentos nutricionais relativamente simples e cuja biomassa pode ser empregada para obtenção de biocompostos com aplicações nutricionais (HENRIKSON, 1994) e de saúde (AMBROSI et al., 2008). Ainda, tem sido relatada a sua aplicação em tratamento de efluentes (MEZZOMO et al., 2010), em processos de biossorção (TEDESCO, 2011, DAL MAGRO et al, 2011, DAL MAGRO et al., 2012) e na produção de biocombustíveis (ANDRADE e COSTA, 2008).

O crescimento de uma população de microalgas é resultado da interação entre fatores biológicos, químicos e físicos (RAVEN et al., 2005). Os fatores biológicos referem-se às próprias taxas metabólicas da espécie cultivada, quanto aos fatores físico-químicos, os principais que afetam o crescimento das microalgas são luz, temperatura, $\mathrm{pH}$, salinidade e disponibilidade de nutrientes, estes são que demandam maior estudo. Não existe um meio de cultivo único para todas as espécies de microalgas, uma vez que cada uma tem suas necessidades específicas (RICHMOND, 2004).

O metabolismo principal da Spirulina platensis é a fotossíntese, sendo a luz solar, sua principal fonte de energia. Por meio da fotossíntese, converte os nutrientes em matéria celular e libera oxigênio. Os nutrientes de que necessita são uma fonte de carbono, nitrogênio, fósforo, potássio, ferro e outros oligoelementos (VONSHAK, 1997).

Semelhantemente ao que ocorre em outros organismos, cada classe de microalgas apresenta sua própria combinação de pigmentos e, conseqüentemente, coloração distinta. Os três principais grupos de pigmentos encontrados na biomassa microalgal são as clorofilas, os carotenóides e as ficobilinas (ficobiliproteínas) (ABALDE et al., 1995).

\section{APLICAÇÕES AMBIENTAIS DAS MICROALGAS}

As microalgas tem sido foco de inúmeras investigações biotecnológicas devido a sua importância econômica, nutricional e ecológica (ANTELO et al., 2010). Nesse tópico, estão apresentadas algumas das aplicações ambientais das microalgas. 


\subsection{Fixação de $\mathrm{CO}_{2}$ oriundo de termelétricas}

A fotossíntese é a principal rota de fixação de carbono da Spirulina platensis, sendo a luz solar sua principal fonte de energia. Por meio da fotossíntese, converte os nutrientes em matéria celular e libera oxigênio. Os nutrientes de que necessita são uma fonte de carbono, nitrogênio, fósforo, potássio, ferro e outros oligoelementos (VONSHAK, 1997).

A biofixação de dióxido de carbono $\left(\mathrm{CO}_{2}\right)$ por microalgas tem provado ser um método eficiente e econômico, principalmente devido à capacidade fotossintética desses micro-organismos ao uso deste gás como fonte de nutrientes para o seu desenvolvimento. Rosa et al. (2011) estudaram o crescimento das microalgas Spirulina LEB18 e Chlorella kessleri, expostas a condições controladas e não controladas, com a injeção de diferentes concentrações de $\mathrm{CO}_{2}$. Verificaram que a maior concentração de biomassa e fixação máxima diária foram obtidas para Spirulina LEB18 na cultura que foi preparada em condições não-controladas com uma injeção de $6 \%(\mathrm{v} / \mathrm{v})$ de $\mathrm{CO}_{2}$. C. kessleri teve taxa de crescimento máximo específico quando cultivada com $18 \%$ (v/v) de $\mathrm{CO}_{2}$ em condições de cultivo não-controladas.

Radmann et al. (2011) realizaram estudo e desenvolveram planta piloto para biofixação de $\mathrm{CO}_{2}$ oriundo da Usina Termelétrica Presidente Médici, localizada no município de Candiota/RS com o objetivo de utilizar gás de combustão da usina para o cultivo das microalgas Spirulina sp. LEB-18 e Scenedesmus obliquus LEB-22, determinando suas características cinéticas e capacidade de fixação de $\mathrm{CO}_{2}$. Nesse estudo observaram que a utilização de gás de combustão da usina termelétrica incrementou em $35 \%$ a produção de biomassa ao final do cultivo de Spirulina sp. LEB-18, com redução de $24,2 \%$ da concentração de $\mathrm{CO}_{2}$ do gás de combustão, sendo biofixado $5,7 \%$ do $\mathrm{CO}_{2}$ para o crescimento das microalgas. A biomassa final das microalgas $S$. obliquus LEB-22 e Spirulina LEB-18 cultivadas com gás de combustão apresentou 6,2 e 4,8\% de lipídios, e 40,6 e 46,8\% de proteínas, respectivamente. Os resultados mostram que as microalgas podem ser cultivadas em plantas de energia elétrica para biofixar o $\mathrm{CO}_{2}$ proveniente do gás de combustão de carvão e contribuir para redução do aquecimento global.

Morais e Costa (2007) testaram em fotobiorreatores tubulares a capacidade de biofixação de $\mathrm{CO}_{2}$ por microalgas Scenedesmus oblíquo e Spirulina sp. em concentrações de situação limitada e em excesso de $\mathrm{CO}_{2}$. A Spirulina apresentou os melhores resultados em todos os parâmetros avaliados, dentre eles a taxa de crescimento específica, produtividade e biofixaçao de $\mathrm{CO}_{2}$.

\subsection{Tratamento de efluentes}

A composição dos efluentes pode variar de acordo com sua origem. Muitos efluentes podem conter grande quantidade de matéria orgânica, ou ainda apresentar altas concentrações de metais tóxicos, representando um grave problema para o meio ambiente (DAL MAGRO et al., 2011).

Mezzomo et al. (2010) utilizaram efluente de suíno, rico em fósforo e nitrogênio inorgânicos, para a produção de biomassa de microalga Spirulina platensis, no qual verificaram que a cultura de Spirulina em efluente suíno demonstrou a possibilidade do seu uso na remoção de DQO e fósforo, além da produção de biomassa, podendo ser uma possível solução para o impacto ambiental gerado pela descarga de efluentes em fontes naturais. $\mathrm{O}$ estudo destacou que a biomassa produzida pode ser adicionada a rações de peixes, os quais podem ser utilizados na formulação de produtos cárneos.

Frente a essa problemática tem-se intensificado os estudos baseados em processos biológicos para tratamento de efluentes, surgindo assim, a biossorção que consiste na absorção de metais tóxicos por microrganismos (QUINTELAS et al., 2008). Esse processo apresenta-se como uma tecnologia promissora e em atual expansão (MÓDENES et al., 2009), apresentando vantagens como baixo custo e boa eficiência (DAS et al., 2008). Dentre os micro-organismos utilizados na biossorção, as 
microalgas possuem destaque em função da sua capacidade de retenção e imobilização de metais (DOSCHI et al., 2007).

Para efluentes que apresentam em sua composição metais tóxicos, Dal Magro e colaboradores (2011) utilizaram a biomassa ativa da microalga Spirulina patensis na remoção de cromo (VI) e DQO, obtendo resultados satisfatórios, uma vez que a microalga Spirulina apresentou capacidade de biossorção de Cromo (VI) de $40 \%$ a $60 \%$ e remoção de DQO de 60 a 70\%. Aneja et al. (2010) avaliaram a biossorção de $\mathrm{Pb}^{+2}$ e $\mathrm{Zn}^{+2}$ de uma solução aquosa contendo diferentes concentrações desses metais, através da biomassa seca da Spirulina sp., onde atingiram índices de biossorção de 82 $\%$ para $\mathrm{Pb}^{+2}$ e de $90 \%$ para $\mathrm{Zn}^{+2}$. Gokhale et al. (2009) realizaram ensaios de biossorção de cromo (VI) em colunas empacotadas utilizando a biomassa seca da Spirulina platensis como material adsorvente, atingindo, em condições experimentais otimizadas, a remoção de até $99 \%$ do metal para uma solução contendo $100 \mathrm{mg}$. $\mathrm{L}^{-1}$ de cromo (VI). Siva Kiran et al. (2012) avaliaram a capacidade da biomassa ativa da Spirulina (Arthospira) indica na biossorção de $\mathrm{Cd}^{+2}$, alcançando remoções de até 93,9\% desse metal, sendo que a taxa de remoção aumentou com o aumento da concentração inicial do metal.

Para verificar o efeito causado por metais tóxicos no crescimento de microalgas, Belokobylsky et al. (2004), submeteram a Spirulina platensis ao crescimento na presença de Se (VI) e Cr (III), onde avaliaram o efeito dos metais separadamente e de forma conjugada, concluindo que a acumulação de $\mathrm{Cr}$ (III) foi maior que a acumulação de Se (VI) e a presença dos dois metais, simultaneamente, afetou a taxa de crescimento da biomassa sem alterar sua morfologia e conteúdo protéico.

\subsection{Produção de biocombustíveis de microalgas}

De acordo com Vadusevan e Fu (2010), com o consumo atual as reservas mundiais de óleo estarão exauridas em 40 anos e de gás em 60 anos. Este fato associado ao aumento do efeito estufa e da temperatura global torna necessário o desenvolvimento de tecnologias para a produção de biocombustíveis.

Segundo Varfolomeev e Wasserman (2011), a crise energética de 1970 catalisou o início dos estudos relacionados à produção de biocombustíveis microalgais. As microalgas podem ser utilizadas para a produção de biometano, biodiesel, biohidrogênio e bioetanol. O uso de microalgas para a produção de biocombustíveis é, desta forma, uma alternativa aos combustíveis fósseis.

A produção de biocombustíveis a partir de microalgas baseia-se primeiramente na produção de biomassa com elevadas produtividades. No caso do uso para a produção de biodiesel, necessita-se ainda que esta biomassa apresente elevados percentuais de lipídios, o que parece ser contraditório, visto que a maioria das espécies que apresentam elevadas produtividades em biomassa não são capazes de acumular lipídios (Montero et al., 2011). Entretanto, grandes avanços tem sido obtidos por pesquisadores no mundo todo através de cultivos em fotobiorreatores, capazes de aumentar a produtividade em biomassa (VARFOLOMEEV e WASSERMAN, 2011).

As principais formas de produção de biocombustíveis microalgais são:

a) pirólise: a biomassa seca é destruída na ausência de oxigênio em temperaturas elevadas, levando a formação de benzeno, hidrocarbonetos aromáticos. O uso de microalgas é mais vantajoso do que a pirólise de lignocelulósicos porque pode ser realizada em temperaturas inferiores $\left(450-550^{\circ} \mathrm{C}\right)$ e mais rapidamente;

b) liquefação termomecânica: a biomassa úmida é utilizada em temperaturas de $300^{\circ} \mathrm{C}$ e 10MPa de pressão com carbonato de sódio como catalisador para a realização da conversão em óleos;

c) Gaseificação e combustão direta: oxidação na presença de oxigênio e água a elevadas temperaturas $\left(800-1000^{\circ} \mathrm{C}\right)$; 
d) Obtenção de biodiesel: a biomassa microalgal é utilizada para a extração dos lipídios intracelulares, os quais são utilizados nas reações de esterificação para a produção de alquil ésteres de ácidos graxos. Para esta aplicação, é necessário o uso de espécies capazes de acumularem lipídios;

e) Obtenção de bioetanol: a biomassa microalgal é utilizada como fonte de carboidratos, os quais são hidrolisados enzimaticamente a partir de amilases, celulases e pectinases para conversão em carboidratos simples, os quais são posteriormente fermentados por Saccharomyces cerevisiae. Para esta aplicação, características como acúmulo de carboidratos e parede celular branda são importantes (VARFOLOMEEV e WASSERMAN (2011).

As vantagens do uso de microalgas na produção de biocombustíveis são:

a) rápido crescimento e elevada concentração de lipídios;

b) sem requerimento por terras aráveis, sem conflito com a produção de alimentos;

c) mecanismo fotossintético similar ao das plantas superiores convertendo $\mathrm{CO}_{2}$ em carboidratos e lipídios;

d) remoção de grandes quantidades de $\mathrm{CO}_{2}$ do meio ambiente;

e) podem ser produzidas a partir de resíduos ou efluentes;

f) pode-se manipular geneticamente a fim de aumentar a fotossíntese e a concentração de triacilgliceróis, a fim de direcionar a biomassa para a produção de biodiesel;

g) emissão menor de dióxido de enxofre, óxido nítrico e outros contaminantes em comparação com diesel (GONG e JIANG, 2010; WIJFEELS e BARBOSA 2010).

\subsubsection{Produção de bioetanol}

O etanol é produzido pela fermentação de biomassa de diversas fontes, variando de plantas e resíduos de agroindustriais da agricultura (XUAN et al., 2009).

O princípio da produção de etanol por microalgas consiste em o cultivo de micro-organismos, a colheita de células, preparação de fermentação da biomassa, e processo de extração do etanol. A preparação da biomassa pode ser realizada por meio de equipamento mecânico ou enzimas que quebram as paredes das células, tornando o mais disponiveis os hidratos de carbono, bem como quebrar as grandes moléculas de carboidratos. Quando as células são quebradas, o fermento Saccharomyces cerevisiae é adicionado à biomassa e fermentação começa. Desta forma, o açúcar é convertido em etanol por leveduras (COSTA e MORAIS, 2011). O processo de destilação é usado para purificar o etanol (AMIN, 2010). Etanol produzido por microalgas pode ser purificada e usada como combustível e o $\mathrm{CO}_{2}$ pode ser reciclado, usando-o como um nutriente para o cultivo de microalgas ou utilização de biomassa residual no processo de de digestão anaeróbia (HARUN et al., 2010b).

As microalgas são uma fonte potencial de substrato fermentável uma vez que, de acordo com as condições de crescimento, eles podem ter altos níveis de compostos de carbono em sua composição, diretamente disponível para a fermentação ou após pré-tratamento. Pode-se produzir etanol a partir de várias microalgas: como Chamydomonas sp., Chlorella sp., Oscillatoria sp., Cyanothece sp. e S. platensis (UENO et al., 1998). Bactérias, leveduras ou fungos também são usados para fermentar carboidratos para produzir etanol em condições anaeróbias. No entanto, juntamente com o etanol, produzem outros compostos como $\mathrm{CO}_{2}$ e $\mathrm{H}_{2} \mathrm{O}$, e o teor máximo é de $0,51 \mathrm{~kg}$ de etanol e 0,49 $\mathrm{kg}$ de $\mathrm{CO}_{2}$ por $\mathrm{kg}$ de glicose (COSTA e MORAIS, 2011).

A microalga Chorella vulgaris pode ser usada como uma fonte de etanol devido a seu alto teor de carboidratos, com a conversão eficiência acima de 65,0\% (COSTA e MORAIS, 2011). Ueno et al. (1998) obtiveram a máxima formação de etanol a partir de Chlorella sp. cultivada em $30,0^{\circ} \mathrm{C}$ de 448.0 $\mu \mathrm{mol}^{-1}$ em peso seco e quando a temperatura foi reduzida para $20,0^{\circ} \mathrm{C}$ a concentração de etanol foi $196.0 \mathrm{mmol}^{-1} \mathrm{em}$ peso peso. A produção de etanol diminuiu quando a temperatura foi aumentada para 
$35,0^{\circ} \mathrm{C}$ e foi completamente inibido em $45,0^{\circ} \mathrm{C}$. A determinação da atividade enzimática em $35^{\circ} \mathrm{C}$ foi menor que em $25^{\circ} \mathrm{C}$, indicando que as enzimas são ativadas em baixas temperaturas.

\subsubsection{Produção de biodiesel}

O uso contínuo de combustíveis originados de petróleo é agora amplamente reconhecido como insustentável uma vez que suas reservas são finitas e devido também a sua contribuição para o acúmulo de dióxido de carbono no ambiente. O biodiesel derivado de oleaginosas é uma alternativa renovável potencial, mas as microalgas parecem ser a única fonte de biodiesel renovável que é capaz de atender a demanda global de combustíveis para transportes, uma vez que sua produtividade de óleo muitos excede em muito a produtividade de óleo das culturas oleaginosas (CHISTI, 2007).

Existem diversas pesquisas no sentido de desenvolver biocombustíveis, uma fonte atraente de energia, haja vista, cada vez mais se faz necessário reduzir as emissões de carbono. Já são produzidos biocombustíveis a partir de cana-de-açúcar e oleaginosas como milho, soja, colza, palma e girassol, no entanto estas culturas necessitam de grandes quantidades terras agricultáveis e com o passar do tempo podem competir com a produção de culturas alimentares. Em virtude disso, nos últimos 2-3 anos a produção de biodiesel de microalgas tem tido um grande interesse, uma vez que a produtividade é bem mais elevada do que as plantas terrestres, podendo algumas delas acumular grandes quantidades de triacilgliceróis (SCOTT et al., 2010).

Existem inúmeros tipos de micro-organismos, tais como microalgas, bacilos, fungos, entre outros, mas nem todos possuem características favoráveis à produção de lipídios para a aplicação na produção de biodiesel. As microalgas destacam-se por apresentarem, em alguns casos, compatibilidade na relação de seu óleo produzido ao óleo vegetal utilizado no processo de transesterificação (MENG et al., 2009; HUANG et al., 2009).

O óleo extraído de microalgas apresenta características semelhantes as dos óleos de plantas oleaginosas e se enquadra dentro das principais características exigidas pela ANP (Agencia Nacional de Petróleo) para qualidade do biodiesel, como o ponto de fulgor mínimo de $115^{\circ} \mathrm{C}$ e baixo índice de acidez (menor que $0,8 \mathrm{mg} \mathrm{KOH} / \mathrm{g}$ ) (TEIXEIRA, 2008). Entre as diversas matérias-primas para a produção de biodiesel, a biomassa de microalgas é aquela que apresenta a possibilidade de produção de biodiesel que permitirá a substituição total do diesel (cerca de 40 bilhões de litros por ano) e de modo ambientalmente sustentável (TEIXEIRA e MORALES, 2006).

As microalgas produzem compostos poliinsaturados, o que leva à diminuição da estabilidade do biodiesel produzido, entretanto, devido à presença de ácidos graxos poliinsaturados, uma vantagem apresentada pelo biodiesel de microalgas é o alto rendimento em temperaturas baixas, característica que não é apresentada pelo biodiesel de oleaginosas convencionais, as quais apresentam pouco rendimento em temperaturas relativamente baixas (PÉREZ, 2007).

O acúmulo de lipídios em microalgas para a produção de biodiesel tem sido um foco atual de trabalho de inúmeros pesquisadores em todo o mundo. A utilização de lipídios de microalgas, segundo inúmeros autores, apresenta vantagens em comparação com as fontes convencionais de lipídios, tais como a elevada produtividade em lipídios por área cultivada, em comparação com culturas oleaginosas agriculturáveis; capacidade de sintetizar e acumular grandes quantidades de lipídios neutros; elevadas taxas de crescimento (por exemplo, duplicações 1-3 por dia); crescimento em ambientes inóspitos, os quais não são agriculturáveis; utilização de fontes de nutrientes, tais como nitrogênio e fósforo, de uma variedade de fontes de águas residuais, contribuindo para o tratamento destas águas residuárias; sequestro de $\mathrm{CO}_{2}$; produção de co-produtos de elevado valor agregado (por exemplo, biopolímeros, proteínas, polissacarídeos, pigmentos, alimentação animal, fertilizantes e $\mathrm{H}_{2}$ ); crescimento em fotobiorreatores durante todo o ano com uma produção anual de biomassa com produtividade, com base na superfície, superior ao dos ecossistemas terrestres, por cerca de dez vezes (HU et al., 2008; WIJFFELS e BARBOSA, 2010; SCOTT et al., 2010). 
A produção de biodiesel a partir de microalgas entretanto, requer que a tecnologia de produção destes microrganismos seja escalonada em três vezes com custos cerca de 10 vezes menores.

Segundo Gong e Jiong (2010), 1 barril de petróleo tem um custo aproximado de 100 dólares. Para que a biomassa microalgal rica em óleo possa ser competitiva deveria custar 340 dólares/ton. Entretanto, o custo atual de 1 tonelada de biomassa é de 3000 a 3800 dólares em fotobiorreatores. Pode-se chegar a valores em torno de 500 dólares se a produção for aumentada. Se a biomassa contiver $30 \%$ de lipídios, o preço de 1 tonelada de óleo será de aproximadamente 1500 dólares, havendo um custo de 2,8 dólares por litro. Para que o biodiesel seja competitivo o preço do óleo derivado de biomassa de microalga precisa ser de 0,48 dólares por litro.

Para tanto, a implementação de reatores, a utilização de fontes de nitrogênio e fósforo de baixo custo, o desenvolvimento de conhecimento acerca das rotas metabólicas de acúmulo de lipídios baseados na biologia molecular são fatores imprescindíveis (WIJFFELS e BARBOSA, 2010). Ainda, a implementação dos métodos de extração de lipídios, utilizando menor quantidade de solventes com a diminuição da extração de impurezas como a clorofila, são etapas a serem otimizadas (SCOTT et al., 2010).

\subsubsection{Produção de biossurfactantes de microalgas}

Os surfactantes são compostos anfipáticos, que possuem um grupo hidrofílico (polar) e um grupo hidrofóbico (apolar), que são geralmente hidrocarbonetos. Esses grupos normalmente têm diferentes graus de polaridade e ligações de hidrogênio, tendendo a distribuir-se nas interfaces entre as fases fluidas ocasionando interação água/óleo ou óleo/água, proporcionando a formação de um filme molecular que reduz a tensão superficial e interfacial. Essas características dão aos surfactantes propriedades únicas como detergência, capacidade de dispersão de fases, emulsificação, formação de espuma, lubrificação, molhabilidade e solubilização. São sintetizados a partir do petróleo (DESAI e BANAT, 1997; NITSCHKE e PASTORE, 2002).

Já os biossurfactantes são compostos tensoativos que são produzidos extracelularmente ou como parte da membrana celular de microrganismos como bactérias, fungos e leveduras (MULLIGAN, 2005) e que apresentam as mesmas características surfactantes dos produzidos sinteticamente, tais como diminuição da tensão superficial e alta capacidade emulsificante (NITSCHKE e PASTORE, 2002).

Os biossurfactantes possuem em sua estrutura uma porção hidrofílica composta de aminoácidos ou peptídeos ânions ou cátions, mono, di ou polissacarídeos e uma porção hidrofóbica constituída de ácidos saturados, insaturados e ácidos graxos hidroxilados ou alcoóis graxos (DESAI e BANAT, 1997) de cadeias longas (MUTHUSAMY et al., 2008).

A composição lipídica da biomassa microalgal é composta de tipicamente por glicerol, açúcares ou bases esterificadas e ácidos graxos contendo entre 12 e 22 carbonos, podendo ser tanto saturados, quanto mono ou poliinsaturados e nas microalgas, os ácidos graxos correspondem a maior fração dos lipídios e, em algumas espécies, os ácidos graxos poliinsaturados (PUFA) representam entre 25 e 60\% dos lipídios totais (BECKER, 1988; BROWN, 1991; BECKER, 2004 apud DERNER, 2006).

Os lipídios microalgais podem ser classificados em polares (componentes de membranas, na forma de fosfolipídios e glicolipídios) e neutros (carotenóides, tri, di e monoacilgliceróis e ceras). Enquanto os últimos são os mais facilmente convertidos em biodiesel, os primeiros são os que apresentam maior potencial de uso como biossurfactantes.

Não há relatos na literatura da utilização de biossurfactantes microalgais em processos de biorremediação. Dada a sua atoxicidade, torna-se importante que esta classe de lipídios microalgais seja estudada, uma vez que as microalgas permitem a concepção de um conceito de sustentabilidade ambiental. 


\section{CONSIDERAÇÕES FINAIS}

Visto os problemas ambientais decorrentes da poluição, evidencia-se a necessidade de encontrar novas alternativas que venham a prevenir e controlar essa poluição de forma eficiente, evitando a degradação ambiental. Os processos biológicos apresentam características apropriadas para auxiliar no combate à poluição, tornando os micro-organismos objetos de diversos estudos e pesquisas.

Nesse cenário, a microalga Spirulina platensis tem sido bastante explorada e vem demonstrando boa capacidade para auxiliar na proteção ambiental. A vantagem de seu uso na remoção de matéria orgânica e DQO de efluentes é que, devido a sua composição química rica em proteínas, vitaminas, ácidos graxos poliinsaturados e pigmentos, esta biomassa pode ser utilizada para o uso em aquicultura ou ser destinada a ração animal. A biomassa obtida a partir do tratamento de efluentes ricos em metais tóxicos, por outro lado, não apresenta esta aplicação.

Com relação à biofixação de $\mathrm{CO}_{2}$, as microalgas, por seu aparato fotossintético, são capazes de fixar mais $\mathrm{CO}_{2}$ do que cultivos de plantas. No caso do uso da microalga Spirulina a biomassa obtida tem aplicações em diversos setores, como o de alimentos e farmacêutico.

No que concerne ao tema deste trabalho, estes cultivos podem ser direcionados para o acúmulo de lipídios ou carboidratos, os quais têm aplicabilidade na produção de biodiesel, biossurfactantes e bioetanol.

Ainda, a Spirulina, em virtude de suas condições de cultivo em pHs alcalinos, traz benefícios no sentido de poder ser cultivada em tanques abertos utilizando luz solar, ao contrário de outras microalgas, devendo-se estudar aspectos de meios de cultivo e processos de agitação que tornem possível o acúmulo destes compostos em tanques abertos. A facilidade de colheita, devido a sua característica filamentosa, também é um fator a ser considerado, por diminuir os custos de produção.

Considerando-se as microalgas como foco de estudo, considera-se que estes microrganismos possuem um leque de aplicações ainda pouco exploradas, sendo importante a realização de estudos que utilizem seu aparato fotossintético como fonte de energia e obtenção de compostos e processos de alto valor agregado.

\section{REFERÊNCIAS BIBLIOGRÁFICAS}

ABALDE, J. et al. Microalgas: Cultivo y Aplicaciones. Servicio de Publicacions, Universidade da Coruna, 1995. 210p.

AKAR, T.; TUNALI, S. Biosorption characteristics of Aspergillus flavus biomass for removal of $\mathrm{Pb}(\mathrm{II})$ and $\mathrm{Cu}$ (II) ions from an aqueous solution. Bioresource Technology, v. 97, n. 15, p. 1780-1787, 2006.

AMIN, G. A. A Potent Biosurfactant Producing Bacterial Strain for Application in Enhanced Oil Recovery Applications. Journal of Petroleum Environmental Biotechnology, v. 1, n. 2, p. 1-5, 2010.

ANDRADE, M. R.; COSTA, J. A. V. Cultivo da microalga Spirulina platensis em fontes alternativas de nutrientes. Ciência e Agrotecnologia, v. 32, n. 5, p. 1551-1556, 2008.

ANEJA, R.K.; CHAUDHARY, G.; AHLUWALIA, S.S.; GOYAL, D. Biosorption of $\mathrm{Pb}^{2+}$ and $\mathrm{Zn}^{2+}$ by non-living biomass of Spirulina sp. Indian Journal Microbiology, v. 50, n. 4, p. 438-442, 2010. 
ANTELO, F.S.; ANSCHAU, A.; COSTA, J.A.V.; KALIL, S.J. Extraction and Purification of Cphycocyanin from Spirulina platensis in Conventional and Integrated Aqueous Two-Phase Systems. Journal of the Brazilian Chemical Society, v. 21, n. 5, p. 921-926, 2010.

BARCELLOS, F.C.; OLIVEIRA, J.C.; CARVALHO, P.G.M. Investimento ambiental em indústrias sujas e intensivas em recursos naturais e energia. Revista Iberoamericana de Economia Ecológica, v. 12, p. 33-50, 2009.

BELOKOBYLSKY, A.I.; GINTURI, E.I.; KUCHAVA, N.E.; KIRKESALI, E.I.; MOSULISHVILI, L.M.; FRONTASYEVA, M.V.; PAVLOV, S.S.; AKSENOVA, N.G. Accumulation of selenium and chromium in the growth dynamics of Spirulina platensis. Journal of Radioanalytical and Nuclear Chemistry, v. 259, n. 1, p. 65.68, 2004.

CHEN, X.; HU, S.; SHEN, C.; DOU, C.; SHI, J.; CHEN, Y. Interaction of Pseudomonas putida CZ1 with clays and ability of the composite to immobilize copper and zinc from solution. Bioresource Technology, v. 100, n. 1, p. 330-337, 2009.

CIFERRI, O.; TIBONI, O. The biochemistry and industrial potential of Spirulina. Annual Review of Microbiology, v.39, p. 503-26, 1985,

CHISTI, Y. Biodiesel from microalgae. Biotechnology Advances, v. 25, p. 294-306, 2007.

CHISTI, Y. Microalgae: our marine forests. Book reviews. IN: RICHMOND, A. (Ed). Handbook of microalgal culture: biotechnology and applied phycology. Oxford: Blackwell Science, 2004. 566p.

COSTA, J.A.V.; MORAIS, M.G. The role of biochemical engineering in the production of biofuels from microalgae. Bioresource Technology, v. 102, p. 2-9, 2011.

DAL MAGRO, C.; HEMKEMEIER, M.; COLLA, L.M. Remoção de cromo VI e DQO de meio de cultivo adicionado de efluente com elevada concentração de cromo a partir da microalga Spirulina platensis. In: XVIII SIMPÓSIO NACIONAL DE BIOPROCESSOS, 2011, Caxias do Sul. Anais... Caxias do Sul: Editora da UCS, 2011. 1 CD-ROM.

DAS, N.; VIMALA, R.; KARTHIKA, P. Biosorption of heavy metals - An Overview. Indian Journal of Biotechnology, v. 7, p. 159-169, 2008.

DERNER, R.B. Efeito de fontes de carbono no crescimento e na composição bioquímica das microalgas Chaetoceros muelleri e Thalassiosira fluviatilis, com ênfase no teor de ácidos graxos poliinsaturados. 2006. 158f. Tese de doutorado em Ciência dos Alimentos, UFSC, Florianópolis.

DOSHI, H.; RAY, A.; KOTHARI, I.L. Bioremediation potential of live and dead Spirulina: Spectroscopic, kinetics and SEM studies. Biotechnology and Bioengineering, v. 96, n. 6, p. 10511063, 2007.

GADD, G.M. Biosorption: critical review of scientific rationale, environmental importance and significance for pollution treatment. Journal of Chemical Technology \& Biotechnology, v. 84, p. 1328, 2009. 
GOKHALE, S.V.; JYOTI, K.K.; LELE, S.S. Modeling of chromium (VI) biosorption by immobilized Spirulina platensis in packed column. Journal of Hazardous Materials, v.170, p. 735743, 2009.

GONG, Y.; JIANG, M. Biodiesel Production with Microalgae as Feedstock: from Strains to Biodiesel. Biotechnology Letters, v. 33, p. 1269-1284, 2011.

HENRIKSON, R. Microalga Spirulina. Superalimento del futuro. Ediciones S.A. Urano, Barcelona, Espanha. 1994, 222 p.

HU, Q.; SOMMERFELD, M.; JARVIS, E.; GHIRARDI, M.; POSEWITZ, M.; SEIBERT, M.; DARZINS, A. Microalgal triacylglycerols as feedstocks for biofuel production: perspectives and advances. The Plant Journal, v. 54, n. 4, p. 621-639, 2008.

HUANG, G.; CHEN, F.; WEI, D.; ZHANG, X.; CHEN, G. Biodiesel production by microalgal biotechnology. Applied Energy, v. 87, n. 1, p. 38-46, 2010.

MENG, X.; YANG, J.; XU, X.; ZHANG, L.; NIE, Q.; XIAN, M. Biodiesel production from oleaginous microorganisms. Renewable Energy, v. 34, n. 1, p. 1-5, 2009.

MEZZOMO, N.; SAGGIORATO, A.G.; SIEBERT, R.; TATSCH, P.O.; LAGO, M.C.; HEMKEMEIER, M.; COSTA, J.A.V.; BERTOLIN, T.E.; COLLA, L.M. Cultivation of microalgae Spirulina platensis (Arthrospira platensis) from biological treatment of swine wastewater. Ciência e Tecnologia de Alimentos, v. 30, n. 1, p. 173-178, 2010.

MÓDENES, A.N.; PIETROBELLI, J.M.T.A.; QUIÑONES, F.R.E.; SUZAKI, P.Y.R.; ALFLEN, V. L.; KLEN, M.R.S.F. Potencial de biossorção do zinco pela macrófita Egeria densa. Engenharia Sanitária e Ambiental, v. 14, n. 4, p. 465-470, 2009.

MONTEIRO, M.P.C.; LUCHESE, R.H.; ABSHER, T.M. Effect of Three Different Types of Culture Conditions on Spirulina maxima Growth. Brazilian Archives of Biology and Technology, v. 53, n. 2, p. 369-373, 2010.

MONTERO, M.F.; ARISTIZÁBAL, M.; REINA, G.G. Isolation of High-Lipid Content Strains of the Marine Microalgae Tetraselmis suecica for Biodiesel production by Flow Cytometry and Single-Cell Sorting, Journal of Applied Phycology, v. 23, p. 1053-1057, 2011.

MORAIS, M.G.; COSTA, J.A.V. Biofixation of carbon dioxide by Spirulina sp. and Scenedesmus obliquus cultivated in a three-stage serial tubular photobioreactor. Journal of Biotechnology, v. 129, p. 439 - 445, 2007.

QUINTELAS, C.; FERNANDES, B.; CASTRO, J.; FIGUEIREDO, H.; TAVARES, T. Biosorption of $\mathrm{Cr}(\mathrm{VI})$ by three different bacterial species supported on granular activated carbon - A comparative study. Journal of Hazardous Materials, v. 153, p. 799-809, 2008.

RADMANN, E. M. et. al., Cultivo de microalgas para a biofixação de $\mathrm{CO}_{2}$ e obtenção de biocombustíveis. In: XVIII SIMPÓSIO NACIONAL DE BIOPROCESSOS, 2011, Caxias do Sul. Anais... Caxias do Sul: Editora da UCS, 2011. 1 CD-ROM. 
ROSA, A.P.C.; CARVALHO, L.F.; GOLDBECK, L.; COSTA, J.A.V. Carbon dioxide fixation by microalgae cultivated in open bioreactors. Energy Conversion and Management, v. 52, n. 8-9, p. 3071-3073, 2011.

SARAVANAN, A.; BRINDHA, V.; MANIMEKALAI, R.; KRISHNAN, S. An evaluation of chromium and zinc biosorption by a sea weed (Sargassum sp.) under optimized conditions. Indian Journal of Science and Technology, v. 2, n. 1, p. 53-56, 2009.

SCOTT, S.A.; DAVEY, M.P.; DENNIS, J.S.; HORST, I.; HOWE, C.J.; LEA-SMITH, D.J.; SMITH, A.G. Biodiesel from algae: challenges and prospects. Current Opinion in Biotechnology, v. 21, n. 3, p. 277-286, 2010.

SIVA KIRAN, R.R.; MADHU, G.M.; SATYANARAYANA, S.V.; BINDIYA, P. Bioaccumulation of Cadmium in Blue Green Algae Spirulina (Arthrospira) indica. Journal of Bioremediation and Biodegradation, v. 3, n. 3, p. 1-4, 2012.

TEIXEIRA, C.M.; MORALES, E. Microalga como matéria-prima para a produção de biodiesel. Biodiesel o novo combustível do Brasil, 2008.

TEIXEIRA, C.M.; MORALES, E. Um Novo Sistema de Cultivo de Microalgas para a produção de Biodiesel. In: Congresso da Rede Brasileira de Tecnologia do Biodiesel, 1, 2006. Brasília. Anais..., Brasília, 2006.

TOMASELLI. L. Morphology, Ultrastructure and taxonomy of Arthorpira (Spirulina) maxima and Arthrospira (Spirulina) platensis. IN: VONSAHK, A. Spirulina platensis (Arthrospira) Physiology, cell-biology and biotechnology. London: Taylor \& Francis, 1997, p. 1-16.

UENO, Y.; KURANO, N.; MIYACHI, S. Ethanol production by dark fermentation in the marine green alga, Chlorococcum littorale. Journal of Fermentation and Bioengineering, v. 86, n. 1, p. 38-43, 1998.

VARFOLOMEEV, S.D.; WASSERMAN, L.A. Microalgae as Source of Biofuel, Food, Fodder and Medicines. Apllied Biochemistry and Microbiology, v. 47, n.9, p. 789-807, 2011.

VASUDEVAN, P.T.; FU, B. Environmentally Sustainable Biofuels: Advances in Biodiesel Research. Waste Biomass Valor, v.1, p. 47-63, 2010.

VONSHAK, A. Spirulina platensis (Arthrospira) Physiology, cell-biology and biotechnology. London: Taylor \& Francis, 1997, 252 p.

XUAN, J.; LEUNG, M.K.H.; LEUNG, D.Y.C.; MENG, N. A review of biomass-derived fuel processors for fuel cell systems. Renewable and Sustainable Energy Reviews, v. 13, n. 6-7, p. 1301$1313,2009$.

WIJFFELS, R.H.; BARBOSA, M.J. An Outlook on Microalgal Biofuels. Science, v. 329, n. 5993, p. 796-799, 2010. 
Revista CIATEC - UPF, vol.4 (1), p.p.48-60, 2012

XU, R.; MI, Y. Simplifying the Process of Microalgal Biodiesel Production Through In Situ Transesterification Technology. Journal of the American Oil Chemists' Society, v. 88, n. 1, p. 91-99, 2011. 